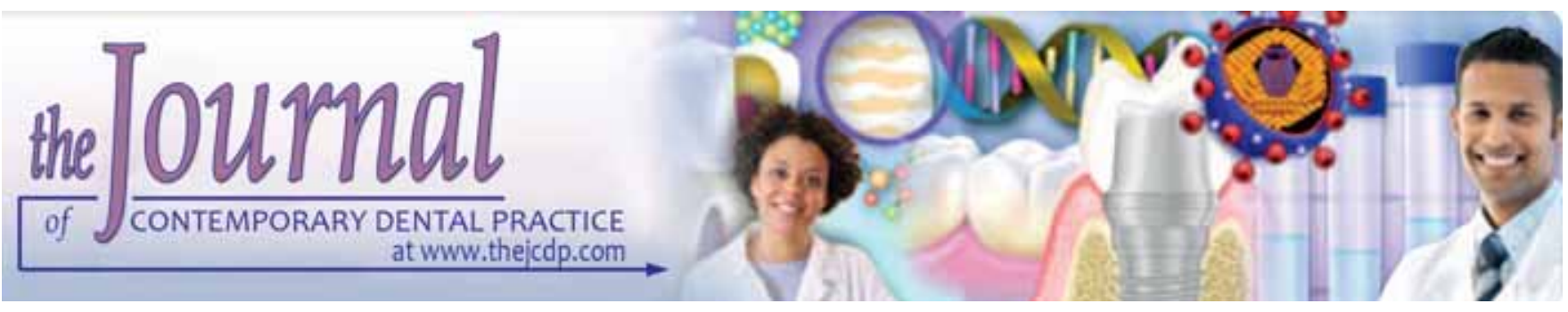

\title{
Frictional Resistance between Orthodontic Brackets and Archwire: An in vitro Study
}

\author{
Nadeem Husain, Avinash Kumar
}

\section{ABSTRACT}

Aim: The purpose of this investigation was to determine the kinetic frictional resistance offered by stainless steel and Titanium bracket used in combination with rectangular stainless steel wire during in vitro translatory displacement of brackets.

Materials and methods: In this study. Brackets: (All brackets used had a torque of $-7^{\circ}$ and an angulation of $\left.0^{\circ}\right)$ : (1) Dynalock (Unitek) 0.018" slot, $3.3 \mathrm{~mm}$ bracket width, (2) Mini Uni-Twin (Unitek) 0.018" slot, $1.6 \mathrm{~mm}$ bracket width, (3) Ultra-Minitrim (Dentaurum) 0.022" slot $3.3 \mathrm{~mm}$ bracket width, (4) Titanium (Dentaurum) 0.022" slot, $3.3 \mathrm{~mm}$ bracket width. WIRES: (1) 0.016 x 0.022" stainless steel (Dentaurum), (2) $0.017 \mathrm{x}$ 0.025 "stainless steel (Unitek), (3) $0.018 \times 0.025$ " stainless steel (Dentaurum), elastomeric modules (Ortho Organisers), 0. 009" stainless steel ligature wires, hooks made of 0.021 x 0.025 " stainless steel wires, super glue to bond the hooks to the base of the bracket, acetone to condition the bracket and wires before testing and artificial saliva. Brackets were moved along the wire by means of an Instron universal testing machine (1101) and forces were measured by a load cell. All values were recorded in Newtons and then converted into gms (1N-102 gm). 200 gm was then subtracted from these values to find out the frictional force for each archwire/bracket combination. For each archwire/ bracket combination three readings were taken under wet and dry condition and also with stainless steel ligature and elastomeric modules separately.

Results: The results showed that narrow brackets generated more friction than wider brackets. Frictional force was directly proportional to wire dimension. Titanium brackets generated more friction than stainless steel brackets. Archwire and bracket ligated with elastomeric module generated more friction than when ligated with stainless steel ligature wire. Frictional forces in the wet condition were greater than in the dry condition for all archwire to bracket combinations.

Conclusion: Frictional force was seen to be inversely proportional to bracket width, frictional force was inversely proportional to bracket width, and in the wet condition were greater than in the dry condition for all archwire to bracket combinations.

Clinical significance: This study of friction is its role in lessening the force actually received by a tooth from an active component such as a spring, loop or elastic. Hence greater applied force is needed to move a tooth with a bracket archwire combination demonstrating high magnitudes of friction compared with one with a low frictional value.

Keywords: Archwire, Bracket, Slot size, SS ligature, Elastomeric module, Wet condition, Dry condition, Instron machine.

How to cite this article: Husain N, Kumar A. Frictional Resistance between Orthodontic Brackets and Archwire: An in vitro Study. J Contemp Dent Pract 2011;12(2):91-99.

\section{Source of support: Nil}

Conflict of interest: None declared

\section{INTRODUCTION}

The earliest recorded experiments on friction were carried out by the versatile genius Leonardo da vinci approximately 450 years ago. According to Palmar, the reason Leonardo's works were never published was related to his method of writing. He states that Coulomb and Morin were credited with the classic laws of friction, reporting that when one body slides or tends to slide over another body, the force that acts to oppose the tendency to move is called the force of friction. This frictional force is always parallel to the surfaces that are in contact. ${ }^{7}$

In contemporary orthodontics, many practitioners utilize sliding mechanics for both closing extraction spaces and aligning irregular teeth. As this procedure requires the teeth to be displaced relative to the archwire, a portion of any force that is applied to move the tooth must be consumed by overcoming the inherent friction of the system. ${ }^{11}$

An understanding of the friction produced during sliding mechanics is critical for the clinicians. Merely increasing the force in an orthodontic appliance will not remedy high friction archwire/bracket couple that is doubling the drawing force will merely double the frictional force. Additionally, excessive amount of archwire/bracket friction may ultimately result in a loss of anchorage or in binding accompanied by little or no tooth movement. ${ }^{11}$ 
Because orthodontic tooth movement is best accomplished by light physiologic forces of long and constant duration, the preferred material for moving a tooth relative to the archwire should be one that produces the least amount of friction at the archwire/bracket interface and has minimal fluctuation in the amount of frictional forces present in the tooth moving system. ${ }^{11}$

An attempt was made in this study to compare the kinetic frictional force generated between various bracket/archwire combinations when ligated with stainless steel ligature wire and elastomeric modules, under dry and wet conditions separately.

\section{AIMS AND OBJECTIVES}

The purpose of this investigation was to determine the kinetic frictional resistance offered by stainless steel and titanium bracket used in combination with rectangular stainless steel wire during in vitro translatory displacement of brackets.

The aims of the study were as follows:

1. To find the frictional force generated between wide 0.018 " slot (Dynalock) and narrow 0.018 " slot (MiniUni-Twin) brackets in combination with $0.016 \times 0.022$ " and $0.017 \times 0.025$ " stainless steel wires under a fixed load of $200 \mathrm{gm}$.

2. To find the frictional forces generated between 0.022" slot stainless steel (Ultra-Minitrim) and 0.022" slot Titanium (Dentaurum) brackets in combination with $0.018 \times 0.025$ " stainless steel wire under a fixed load of $200 \mathrm{gm}$.

3. Both the above studies were done under wet and dry conditions separately. Artificial saliva was used to simulate wet conditions.

4. The method of ligation, i.e. stainless steel ligature wire and elastomeric modules and their effect on frictional forces were also studied with the above combinations.

\section{MATERIALS AND METHODS}

\section{Materials}

1. Brackets: (All brackets used had a torque of $-7^{\circ}$ and an angulation of $0^{\circ}$ ).

- Dynalock (Unitek) 0.018 " slot, $3.3 \mathrm{~mm}$ bracket width

- Mini Uni-Twin (Unitek) 0.018" slot, $1.6 \mathrm{~mm}$ bracket width

- Ultra-Minitrim (Dentaurum) $0.022 "$ slot $3.3 \mathrm{~mm}$ bracket width

- Titanium (Dentaurum) 0.022" slot, $3.3 \mathrm{~mm}$ bracket width.

2. Wires:

- $0.016 \times 0.022 "$ stainless steel (Dentaurum)

- $0.017 \times 0.025^{\prime \prime}$ stainless steel (Unitek)

- $0.018 \times 0.025 "$ stainless steel (Dentaurum)
3. Elastomeric modules: (Ortho Organisers)

4. 0.009" stainless steel ligature wires

5. Hooks made of $0.021 \times 0.025^{\prime \prime}$ stainless steel wires

6. Super glue to bond the hooks to the base of the bracket

7. Acetone to condition the bracket and wires before testing

8. Artificial saliva:

Composition:

- Sodium chloride $-0.4 \mathrm{gm}$

- Potassium chloride-1.21gm

- Sodium dihydrogen phosphate- $0.78 \mathrm{gm}$

- Sodium sulfate-0.005 gm

- Urea-1gm

- Bovine albumin-3.9 gm

- Distilled water-1000 ml

- $\mathrm{pH}-6.7$.

\section{Methods}

The measurements of friction between bracket and archwire were done with the apparatus shown in Fig. 1. A Jig was made which simulated a fixed appliance with the archwire

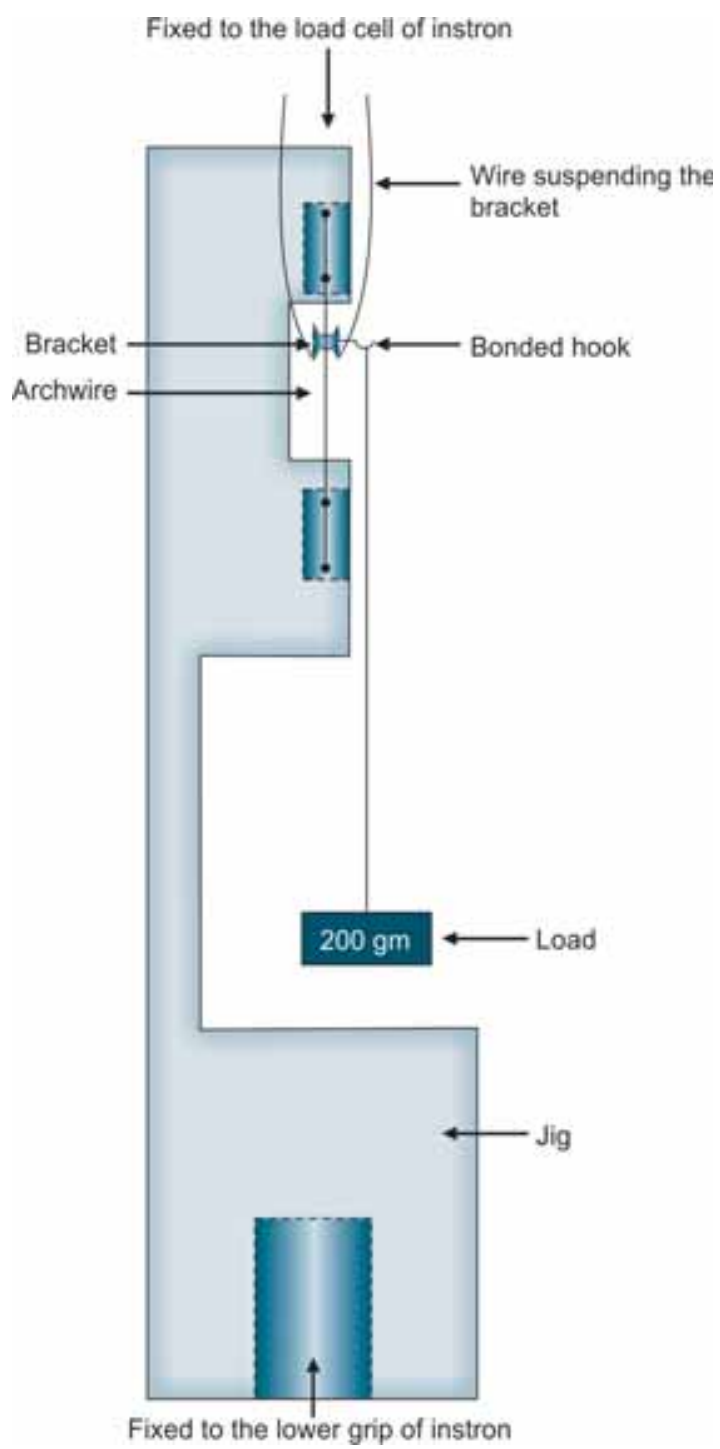

Fig. 1: Diagram showing the set-up used for the study 
in a vertical position. Two ' $\mathrm{L}$ ' shaped plates with two screws each were used to stabilise the arch wire on the jig. A $10 \mathrm{~mm}$ space was cut in the jig to allow the movement of the bracket on the archwire.

All samples to be tested were conditioned with acetone solution to remove the dust particles and the oil layer from over their surfaces. Both 0.018" slot and 0.022" slot brackets were set up in this way using in turn archwires of $0.016 \times$ $0.022 ", 0.017 \times 0.025^{\prime \prime}$ stainless steel in $0.018 "$ slot and $0.018 \times 0.025^{\prime \prime}$ stainless steel in $0.022 "$ slot.

The ligature on the movable bracket was at first fully tightened till it doubled back on itself and then slightly slackened to allow free sliding. A $4 \mathrm{~mm}$ hook was bonded to the base of the bracket with super glue from which a weight of 200 gm was suspended. This suspended weight created a two point contact between the archwire and the bracket. A cut out was made in the lower half of the jig to accommodate this suspended weight so that it does not touch the jig when the bracket is moving on the archwire. All tests were conducted under dry and wet conditions with an Instron universal testing machine. Artificial saliva was constantly sprayed with a needle and syringe on the bracket and the archwire sample when testing under wet conditions (Figs 2 and 3).

The jig was fixed on the lower grip of the Instron machine. The upper grip of the instron is connected to the load cell which suspends the movable bracket by means of a wire. The cross head was adjusted to move upwards at a constant speed of $5 \mathrm{~mm} / \mathrm{min}$. In each test, the bracket was moved a distance of $2.5 \mathrm{~mm}$ across the central space and the load cell reading was recorded on a chart paper. In some cases, the reading rose slightly to a maximum when the bracket was near the center of the archwire. In such cases, the maximum reading was recorded.



Fig. 2: Instron universal testing machine

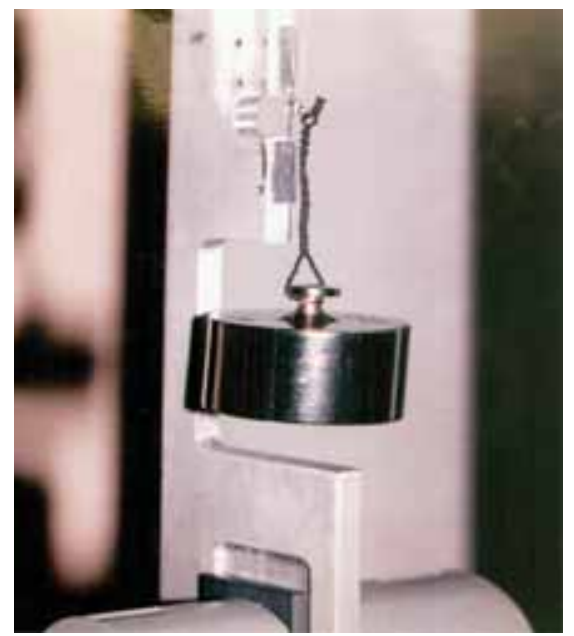

Fig. 3: Mounted jig with bracket archwire and suspended weight

The load cell reading represented the clinical force of retraction that would be applied to a tooth; part of the force would be lost in friction while the remainder was transmitted to the tooth root. The difference between the load cell reading and the load suspended from the bracket hook then represented the friction.

All values were recorded in Newtons and then converted into gm (1N-102 gm). $200 \mathrm{gm}$ was then substracted from these values to find out the frictional force for each archwire/ bracket combination.

For each archwire/bracket combination three readings were taken under wet and dry condition, and also with stainless steel ligature and elastomeric modules separately.

Derivation of a formula to calculate the contact angle between the archwire and the bracket (Fig. 4).

- $\mathrm{B}_{\mathrm{L}}$ - bracket length

- $\mathrm{B}_{\mathrm{W}}$-bracket width

- $\mathrm{W}_{\mathrm{W}}$-wire width

- $\mathrm{O}$ - angle between wire and bracket.

In PQR,

$$
\begin{aligned}
\mathrm{X}^{2} & =\mathrm{B}_{\mathrm{L}}^{2}+\mathrm{B}_{\mathrm{W}}^{2} \\
(\mathrm{PR})^{2} & =(\mathrm{QR})^{2}+(\mathrm{PQ})^{2}
\end{aligned}
$$

In PSR,

$$
\begin{aligned}
\mathrm{X}^{2} & =\mathrm{W}_{\mathrm{W}}{ }^{2}+\left(\mathrm{Z}_{1}+\mathrm{Z}_{2}\right)^{2} \\
(\mathrm{PR})^{2} & =(\mathrm{QR})^{2}+(\mathrm{SR})^{2} \\
\mathrm{~B}_{\mathrm{W}} & =\mathrm{G}+\mathrm{H} \\
\tan \theta & =\frac{\mathrm{G}}{\mathrm{B}_{\mathrm{L}}}
\end{aligned}
$$

Therefore, $\quad \mathrm{G}=\mathrm{B}_{\mathrm{L}} \tan \theta$

Therefore, $\quad \mathrm{H}=\frac{\mathrm{W}_{\mathrm{W}}}{\cos \theta}$

Substituting values of $\mathrm{G}$ and $\mathrm{H}$ in equation 3:

$$
=\mathrm{B}_{\mathrm{L}} \tan \theta+\frac{\mathrm{W}_{\mathrm{W}}}{\cos \theta}
$$




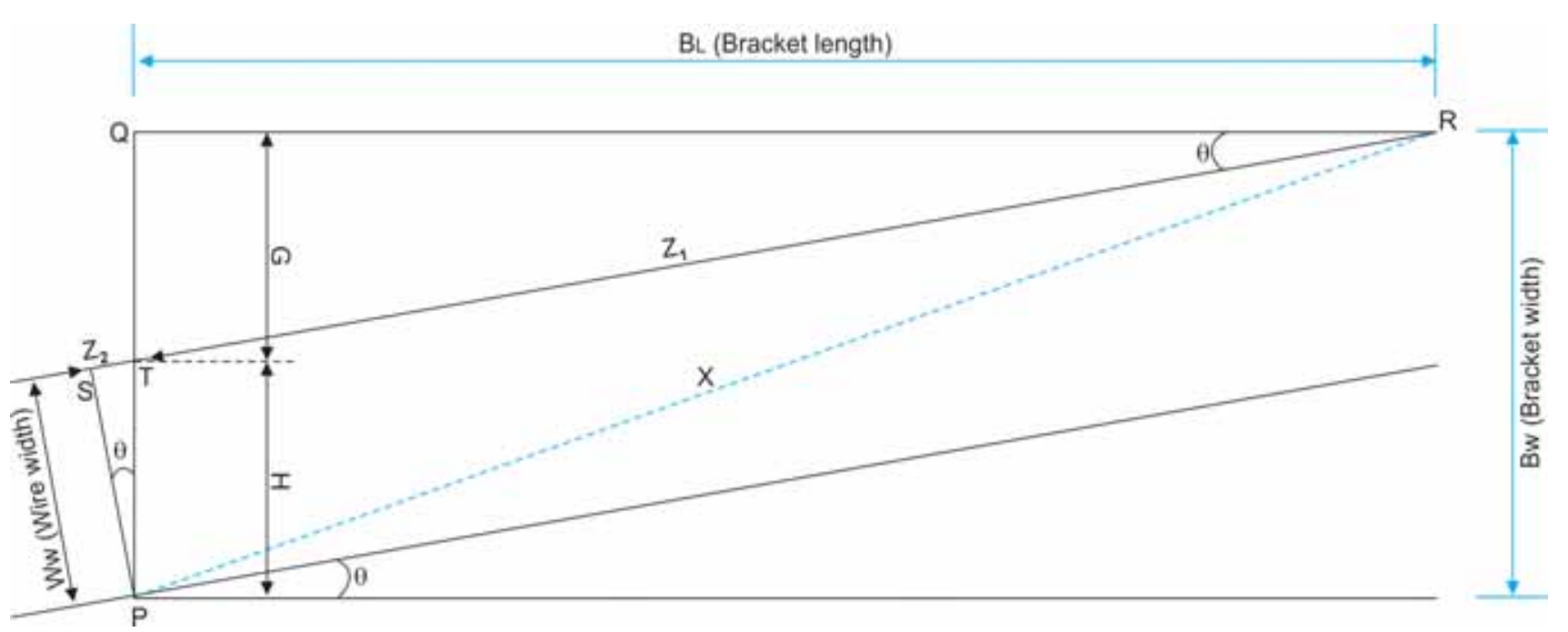

Fig. 4: The contact angle between the bracket and the archwire

$$
\begin{aligned}
\cos \theta & =\frac{\mathrm{B}_{\mathrm{L}}}{\mathrm{Z}_{1}} \\
\mathrm{Z}_{1} & =\frac{\mathrm{B}_{\mathrm{L}}}{\cos \theta} \\
\tan \theta & =\frac{\mathrm{Z}_{2}}{\mathrm{~W}_{\mathrm{W}}}
\end{aligned}
$$

Therefore, $\mathrm{Z}_{2}=\mathrm{W}_{\mathrm{W}} \tan \theta$

Substituting values of $Z_{1}$ and $Z_{2}$ in equation 2 :

$$
\begin{aligned}
\mathrm{X}^{2} & =\mathrm{W}_{\mathrm{W}}^{2}+\frac{\mathrm{B}_{\mathrm{L}}}{\cos \theta}+\mathrm{W}_{\mathrm{W}} \tan \theta \\
\sqrt{\mathrm{X}^{2} \quad \mathrm{~W}_{\mathrm{W}}^{2}} & =\frac{\mathrm{B}_{\mathrm{L}}}{\cos \theta}+\mathrm{W}_{\mathrm{w}} \tan \theta
\end{aligned}
$$$$
\text { Dividing equations } 4 \text { and } 5 \text { : }
$$$$
\begin{aligned}
\frac{\mathrm{B}_{\mathrm{w}}}{\sqrt{\mathrm{X}^{2} \mathrm{~W}_{\mathrm{W}}^{2}}} & =\frac{\mathrm{B}_{\mathrm{L}} \tan \theta+\mathrm{W}_{\mathrm{W}} / \cos \theta}{\mathrm{B}_{\mathrm{L}} / \cos \theta+\mathrm{W}_{\mathrm{W}} \tan \theta} \\
& =\frac{\frac{\mathrm{B}_{\mathrm{L}} \sin \theta}{\cos \theta}+\frac{\mathrm{W}_{\mathrm{W}}}{\cos \theta}}{\frac{\mathrm{B}_{\mathrm{L}}}{\cos \theta}+\frac{\mathrm{W}_{\mathrm{W}} \sin \theta}{\cos \theta}} \\
& =\frac{\frac{\mathrm{B}_{\mathrm{L}} \sin \theta+\mathrm{W}_{\mathrm{W}}}{\cos \theta}}{\frac{\mathrm{B}_{\mathrm{L}} \sin \theta}{\cos \theta}} \\
\text { Let } \mathrm{Y} & =\frac{\mathrm{B}_{\mathrm{w}}}{\sqrt{\mathrm{X}^{2}-\mathrm{W}_{\mathrm{W}}^{2}}}
\end{aligned}
$$

Substituting values of $\mathrm{X}^{2}$ from equation 1

$$
\mathrm{Y}=\frac{\mathrm{B}_{\mathrm{w}}}{\sqrt{\mathrm{B}_{\mathrm{L}}^{2} \quad \mathrm{~B}_{\mathrm{w}}^{2} \quad \mathrm{~W}_{\mathrm{w}}^{2}}}
$$

Therefore, $Y=\frac{B_{L} \sin \theta+B_{W}}{B_{L}+W_{W} \sin \theta}$

$$
\begin{aligned}
\mathrm{Y}\left(\mathrm{B}_{\mathrm{L}}+\mathrm{W}_{\mathrm{W}} \sin \theta\right) & =\mathrm{B}_{\mathrm{L}} \sin \theta+\mathrm{B}_{\mathrm{W}} \\
\mathrm{YB}_{\mathrm{L}}+\mathrm{YW}_{\mathrm{W}} \sin \theta & =\mathrm{B}_{\mathrm{L}} \sin \theta+\mathrm{B}_{\mathrm{W}} \\
\mathrm{YB}_{\mathrm{L}}-\mathrm{W}_{\mathrm{W}} & =\mathrm{B}_{\mathrm{L}} \sin \theta-\mathrm{YW}_{\mathrm{W}} \sin \theta \\
\left(\mathrm{YB}_{\mathrm{L}}-\mathrm{W}_{\mathrm{W}}\right) & =\left(\mathrm{B}_{\mathrm{L}}-\mathrm{YW}_{\mathrm{W}}\right) \sin \theta \\
\sin \theta & =\frac{\mathrm{YB}_{\mathrm{L}} \mathrm{W}_{\mathrm{W}}}{\mathrm{B}_{\mathrm{L}} \mathrm{YW}_{\mathrm{W}}} \\
\sin ^{-1} \frac{\mathrm{YB}_{\mathrm{L}} \mathrm{W}_{\mathrm{W}}}{\mathrm{B}_{\mathrm{L}} \mathrm{YW}_{\mathrm{W}}} & =\theta
\end{aligned}
$$

\section{RESULTS}

The frictional resistance values for all the archwire to bracket combinations are shown in Tables 1 to 4 and Graphs 1 to 4 .

\section{Effect of Bracket Width}

The narrow Mini Uni-Twin brackets with a bracket width of $7.6 \mathrm{~mm}$ generated more frictional force with $0.016 \times$ $0.022^{\prime \prime}$ stainless steel wire, than broader dynalock bracket with a bracket width of $3.3 \mathrm{~mm}$ when tested with the same wire under both wet and dry condition. This shows that frictional force is inversely proportional to the bracket width. Narrow brackets can therefore be expected to provide more friction in clinical use.

\section{Effect of Wire Dimension}

Both Mini Uni-Twin and dynalock brackets generated more friction when the wire dimension was increased from 0.016 $\times 0.022^{\prime \prime}$ stainless steel to $0.017 \times 0.025^{\prime \prime}$ stainless steel under both dry and wet conditions. Frictional force was directly proportional to the wire size.

\section{Effect of Ligation Technique}

All combinations of bracket and archwire under both dry and wet conditions showed more frictional forces with elastomeric module when compared to stainless steel ligature wire. 
Frictional Resistance between Orthodontic Brackets and Archwire: An in vitro Study

\begin{tabular}{|c|c|c|c|c|c|}
\hline \multicolumn{6}{|c|}{ Table 1: Dry conditions } \\
\hline \multirow{2}{*}{$\begin{array}{c}\text { Bracket } \\
\text { (0.018 slot) }\end{array}$} & \multirow{2}{*}{$\begin{array}{c}\text { Bracket } \\
\text { width }\end{array}$} & \multirow[t]{2}{*}{ Wires } & \multicolumn{2}{|c|}{ Frictional force (gm) } & \multirow[t]{2}{*}{ Contact angle } \\
\hline & & & $\begin{array}{l}\text { SS ligature } \\
\text { wire }\end{array}$ & $\begin{array}{l}\text { Elastomeric } \\
\text { module }\end{array}$ & \\
\hline \multirow{2}{*}{ Minitwin (SS) } & $1.6 \mathrm{~mm}$ & $0.016 \times 0.022 "(\mathrm{SS})$ & 146.27 & 188.33 & $1.783^{\circ}$ \\
\hline & & $0.017 \times 0.025 "(\mathrm{SS})$ & 178.93 & 214.47 & $0.897^{\circ}$ \\
\hline \multirow[t]{2}{*}{ Dynalock (SS) } & $3.3 \mathrm{~mm}$ & $0.016 \times 0.022 "(\mathrm{SS})$ & 97.87 & 171.92 & $0.865^{\circ}$ \\
\hline & & $0.017 \times 0.025 "(\mathrm{SS})$ & 129.73 & 199.93 & $0.432^{\circ}$ \\
\hline
\end{tabular}

\begin{tabular}{cccccc} 
& \multicolumn{5}{c}{ Table 2: Dry conditions } \\
Bracket & $\begin{array}{c}\text { Bracket } \\
\text { width }\end{array}$ & Wires & \multicolumn{2}{c}{ Frictional force (gm) } & Contact angle \\
\cline { 4 - 5 } & & & $\begin{array}{c}\text { SS ligature } \\
\text { wire }\end{array}$ & $\begin{array}{c}\text { Elastomeric } \\
\text { module }\end{array}$ \\
\hline Ultra-Mini-Trim (SS) & $3.3 \mathrm{~mm}$ & $0.018 \times 0.025^{\prime \prime}$ (SS) & 64.60 & 90.73 & $1.732^{\circ}$ \\
Titanium (SS) & $3.3 \mathrm{~mm}$ & $0.018 \times 0.025^{\prime \prime}(\mathrm{SS})$ & 80.93 & 120.13 & $1.732^{\circ}$ \\
\hline
\end{tabular}

\begin{tabular}{ccccc} 
& \multicolumn{3}{c}{ Table 3: Wet conditions } \\
\hline $\begin{array}{c}\text { Bracket } \\
\text { (0.018" slot) }\end{array}$ & $\begin{array}{c}\text { Bracket } \\
\text { width }\end{array}$ & Wires & \multicolumn{2}{c}{ Frictional force (gm) } \\
\cline { 3 - 5 } & & & $\begin{array}{c}\text { SS ligature } \\
\text { wire }\end{array}$ & $\begin{array}{c}\text { Elastomeric } \\
\text { module }\end{array}$ \\
\hline Minitwin (SS) & $1.6 \mathrm{~mm}$ & $0.016 \times 0.022^{\prime \prime}(\mathrm{SS})$ & 210.80 & 227.93 \\
& & $0.017 \times 0.025^{\prime \prime}(\mathrm{SS})$ & 218.53 & 247.53 \\
Dynalock (SS) & $3.3 \mathrm{~mm}$ & $0.016 \times 0.022^{\prime \prime}(\mathrm{SS})$ & 139.73 & 195.27 \\
& & $0.017 \times 0.025^{\prime \prime}(\mathrm{SS})$ & 169.13 & 211.60 \\
\hline
\end{tabular}

\begin{tabular}{ccccc} 
& \multicolumn{3}{c}{ Table 4: Wet conditions } \\
\cline { 3 - 4 } Bracket & Bracket & Wires & \multicolumn{2}{c}{ Frictional force (gm) } \\
\cline { 3 - 4 }$(0.022 "$ slot) & width & & SS ligature wire & Elastomeric module \\
\hline Ultra-Mini-Trim (SS) & $3.3 \mathrm{~mm}$ & $0.018 \times 0.025^{\prime \prime}(\mathrm{SS})$ & 90.73 & 123.40 \\
Titanium (SS) & $3.3 \mathrm{~mm}$ & $0.018 \times 0.025^{\prime \prime}(\mathrm{SS})$ & 123.40 & 149.53 \\
\hline
\end{tabular}

\section{Effect of Artificial Saliva}

The frictional forces generated with all bracket to wire combinations and with both ligation techniques increased from the dry to the wet state.

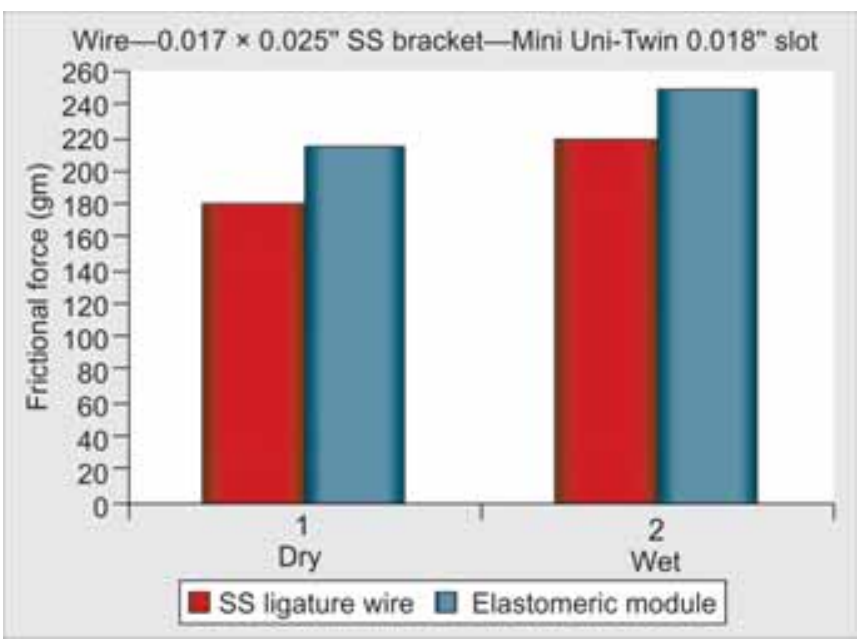

\section{Effect of Bracket Material}

The $0.022^{\prime \prime}$ slot Titanium bracket generated more friction than the 0.022. If slot Ultra-Mini-Trim stainless steel brackets when tested with the same wire specimen under both dry and wet conditions.

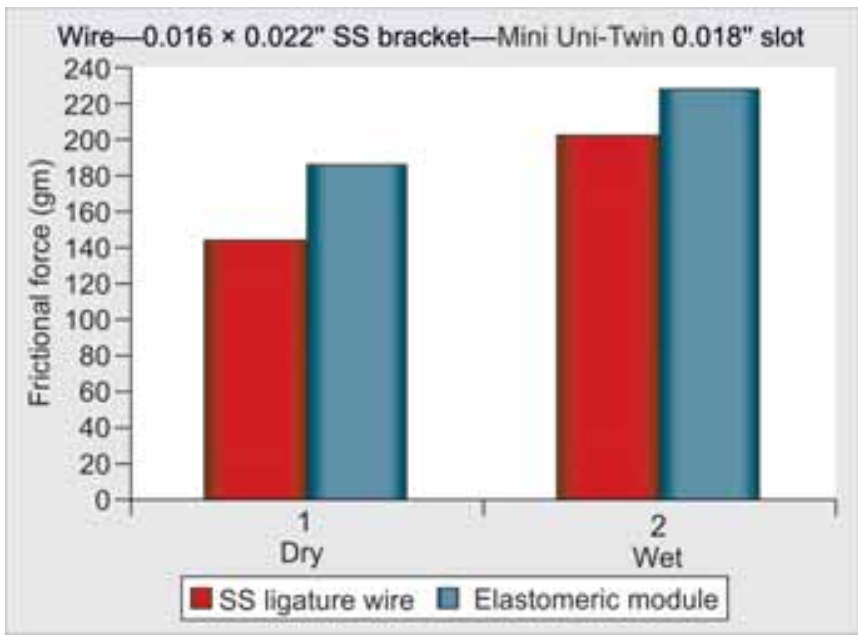

Graph 1: Variable wire dimensions in Mini Uni-Twin SS brackets, 0.018 " slot with SS ligature and elastomeric module in dry and wet conditions 

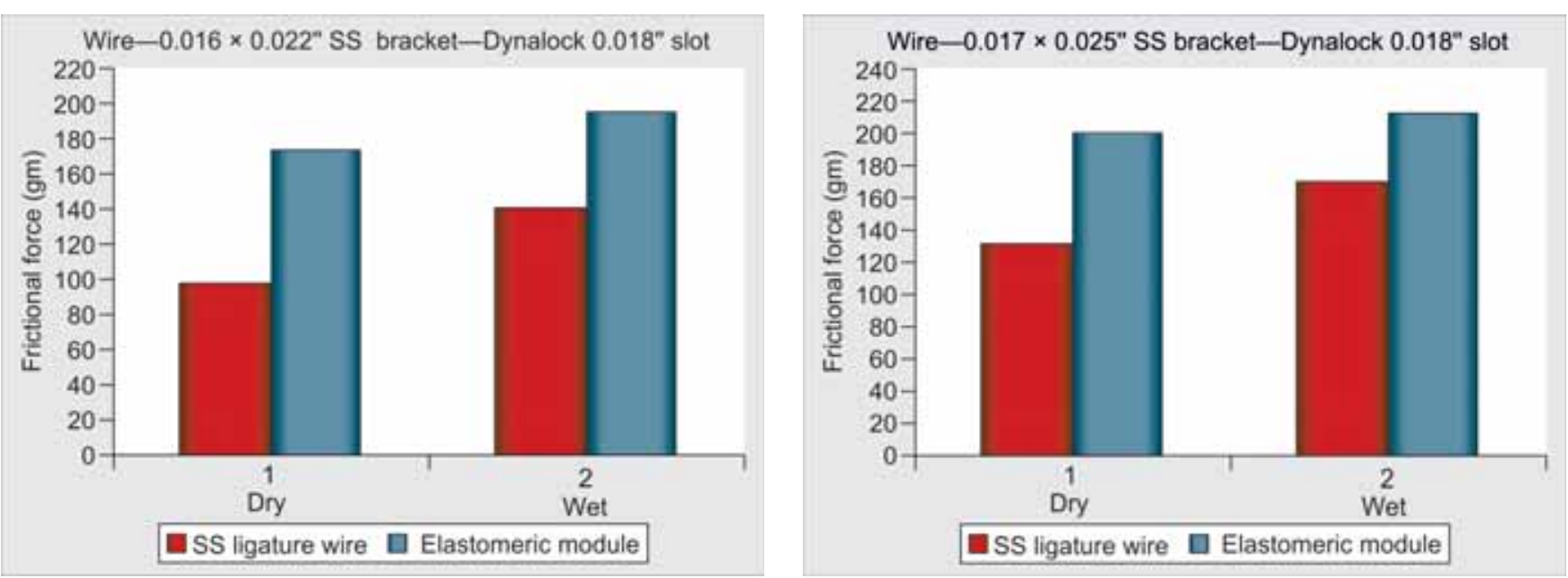

Graph 2: Variable arch wire dimension in Dynalock SS, brackets, 0.018 slot with SS ligature and elactomeric module in dry and wet conditions
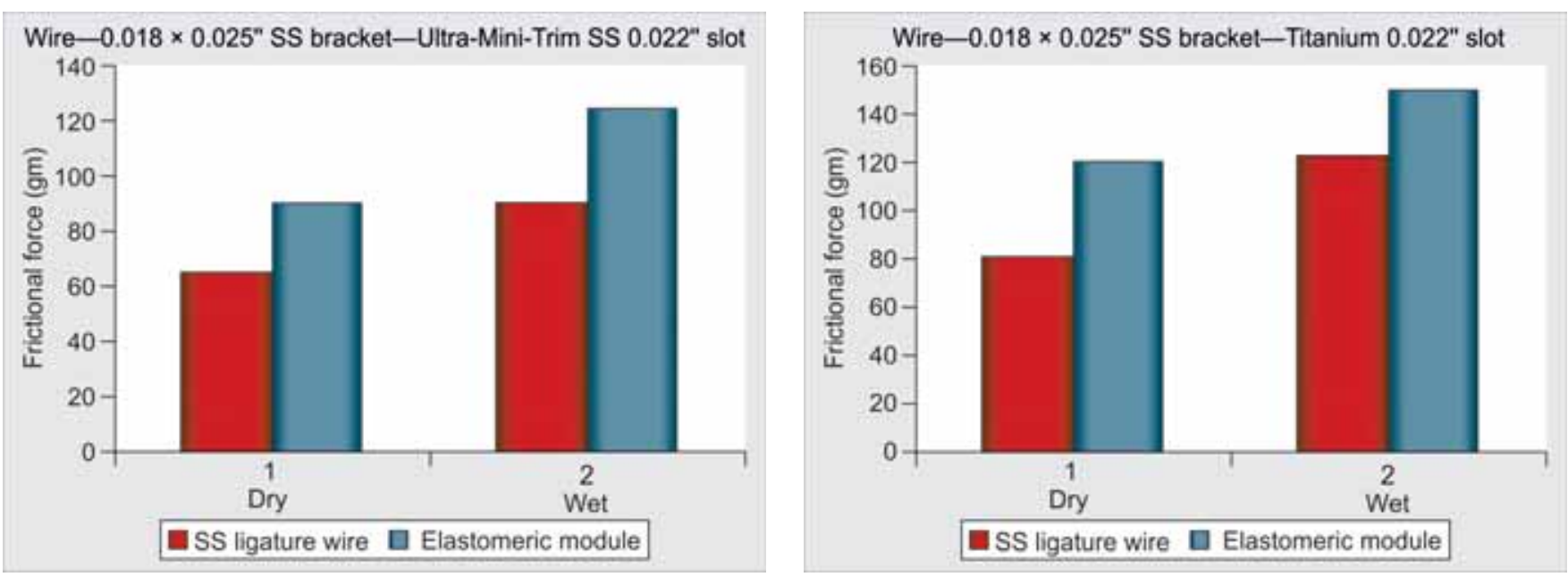

Graph 3: Variable bracket materials SS/titanium with $0.018 \times 0.025$ " SS archwire, 0.022 slot with SS ligature and elastomeric module in dry and wet conditions
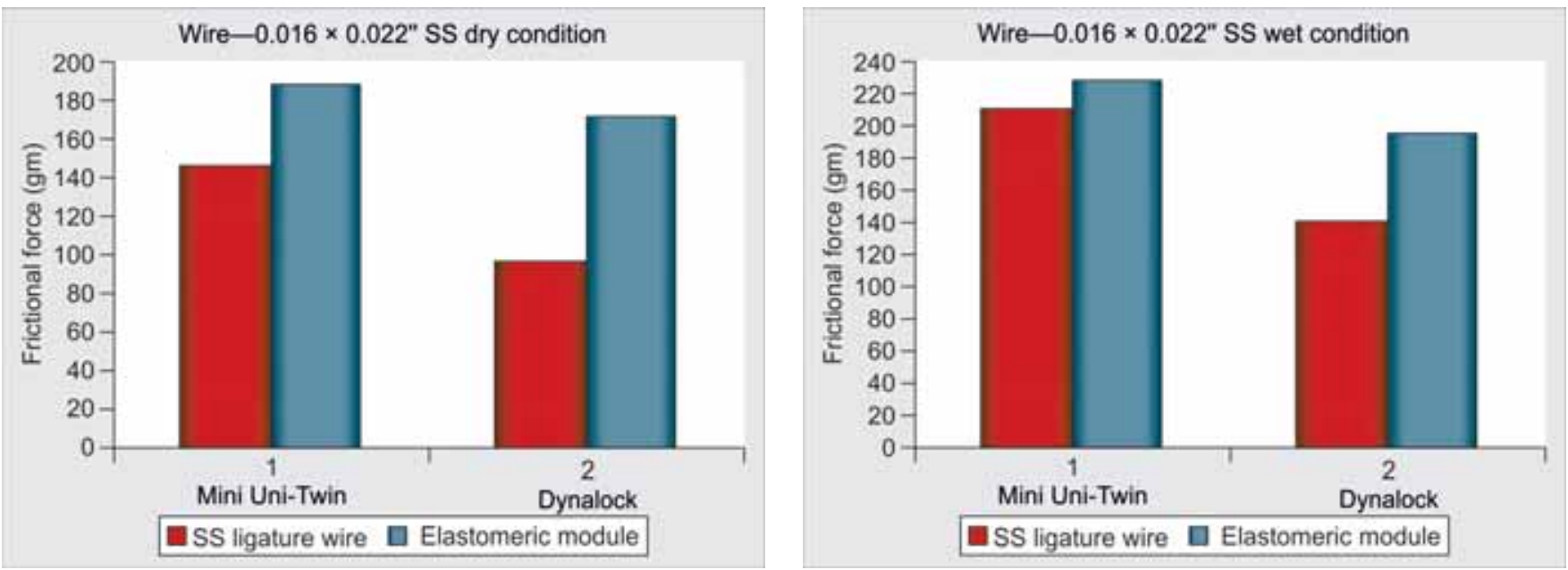

Graph 4: Variable condition dry/wet $0.016 \times 0.022$ " SS archwire in Mini Uni-Twin Dynalock, SS brackets with SS ligature and elastomeric module in dry and wet conditions

\section{DISCUSSION}

Friction is defined as a force tangential to the common boundary of two bodies in contact that resists the motion or tendency to motion of one relative to the other. ${ }^{5}$ Since this force operates in the opposite direction to the mobile body, it is important that frictional forces should be eliminated or minimized when orthodontic tooth movement is being planned. Mesiodistal tooth movement can be accomplished 
by free body movement or by guidance of a tooth along an archwire. The major advantage of the former mechanism is the lack of frictional forces between bracket and archwire. Unfortunately, such a mechanism is associated with undesired tooth rotations in the sagittal and transverse planes, resulting in an increase in the leveling requirements. By contrast, the latter technique of guiding a tooth along an archwire decreases adverse rotating movements but tends to increase friction, which results in a delay in tooth movement, an increase in anchorage requirement, or both.

Several variables have been found to affect the levels of friction between bracket and archwire. These variables may be either mechanical or biologic. Mechanical variables include bracket material, ${ }^{9}$ slot size, ${ }^{3}$ bracket width, ${ }^{3}$ angulation, ${ }^{3,1}$ wire shape, ${ }^{3}$ wire size, ${ }^{3,1}$ wire material, ${ }^{9,7}$ as well as ligature material and force of ligation. ${ }^{3}$ Saliva, plaque, acquired pellicle and corrosion have been implicated as some of the biologic factors that affect bracket wire friction. $^{10}$

Guiding a tooth along an archwire can be divided in four consecutive phases-Drescher. ${ }^{5}$

- Phase l: Before application of force in the mesiodistal direction and on completion of the levelling stage, the archwire lies in the slot, with no conflict.

- Phase 2: Concomitant with force application in the mesiodistal direction, the tooth tips and rotates since the point of force application lies above and buccal to the center of resistance (lower canines).

- Phase 3: Continuous force application sets an elastic deformity in the archwire. The load at the contact points between wire and bracket increases as well as the friction. Thus, a portion of the mesiodistal force is lost. This elastic deformity concurrently produces antitip and antirotational movements of the tooth.

- Phase 4: In an unbalanced situation, a permanent deformity of the archwire can be developed. Obviously, the latter situation should be avoided.

Arch guided tooth movement consists of repeated movements of tipping and uprighting (Phase 1 to 3 ).

For simulation of an archwire guided tooth movement, a full three-dimensional freedom of mobility of the examined body (tooth) is required. Since this facility was not available, a translatory movement of the bracket relative to the archwire was done by suspending a fixed load from the bracket hook which created a two point contact between the bracket and the archwire.

Friction can be either static or kinetic. Static friction is the force needed to start movement, whereas kinetic friction is the force needed to maintain movement once started. Both static and kinetic sliding friction occur in any orthodontic situation in which there is displacement of an archwire through a bracket or a bracket along an archwire over a period of time.

This study has shown that narrow brackets generate greater frictional resistance when compared to wide brackets with the same wire specimen. This finding is in concordance with the finding of Tidy, ${ }^{16}$ Drescher et $\mathrm{al}^{5}$ and Dickson et $\mathrm{al}^{4}$ who explain that, as the bracket width increases, friction reduces due to reduction in tipping, and hence binding, permitted by the wider brackets.

It can be further explained, that as the bracket width decrease, with the wire dimension remaining as constant, the contact angle between the bracket and the archwire increases (Table 1). As the archwire to bracket play increases, there is a greater chance for the tooth to tip. This increased tipping creates a greater conflict between the bracket and the archwire at the contact points which results in increased friction.

This finding is in contrast to the finding of Frank and Nikolai ${ }^{3}$ and Sunil Kapila et al, ${ }^{15}$ who reported an increase in friction with increased bracket width. This finding may be attributed to the use of elastic modules for ligation. Such an arrangement would cause a greater stretching and larger normal force of the ligature with wider bracket, than with narrow brackets and thus, a resultant increase in bracket to archwire friction with wide brackets.

According to this study, the frictional resistance between all bracket to archwire combination is more in wet conditions than in dry conditions. This supported the finding of Pratten et al, Stannard et a1, ${ }^{9}$ Kusy and Whitley, ${ }^{12}$ Alison Downing, ${ }^{2}$ Edward et $\mathrm{al}^{6}$ and Kusy and Schaffer. ${ }^{11}$

Pratten et al suggest that at high load (undefined), saliva may be forced out from the contacts between the bracket and the archwire, resulting in an increase in friction. Hence, saliva may act as a lubricant at low loads as determined by ligature force. However, according to the engineering literature, it is impossible to force out completely even an oil film from between two plane surfaces, no matter how heavy the load is. The artificial saliva used by Pratten et al was based on carboxymethylcellulose. ${ }^{17}$

Allison Downing et al suggested that lubrication generally reduces friction values for rough surfaces. However, water and other polar liquids (including saliva) are known to increase adhesion or attraction among polar materials and thus increase friction. This phenomenon is thought to occur from increased atomic attraction among ionic species. ${ }^{2}$ This behavior has been observed for several different dental materials in the presence of saliva and has been explained by the adhesion theory of friction (Rabinowicz 1965). If the adhesion theory of friction is accepted, it appears that the adhesion of asperites of like surfaces takes place more readily in the presence of saliva, 
and the subsequent force necessary for their rupture is higher. The presence of a polar liquid, such as water, improves the opportunity for adhesion of surface asperites, thus increasing the frictional force. The coefficients of friction of saliva and water are similar, indicating it would seem that saliva is a poor lubricant.

Andreasen and Quevedo ${ }^{1}$ concluded that saliva played an insignificant role in lubricating the surface of the archwire in the bracket slot. The explanation they gave for this finding was that the archwire touches the bracket at only two points, where the pressure is relatively great. The lubricant could be expelled from the area of contact, allowing no lubrication between the archwire and bracket to exist.

Baker et al ${ }^{10}$ found that artificial saliva acted as a lubricant bringing about 15 to $19 \%$ reduction in force values, when measuring the static frictional forces generated between stainless steel brackets and archwire. These findings were supported by the studies of Tselepsis et al. ${ }^{13}$

Baker advocates the use of saliva substitute in patients having xerostomia and who are undergoing orthodontic treatment. Xerostomia can be associated with mouth breathing, aging, stress, depression, gastrectomy, vagotomy, states of chronic anxiety and as the result of drug administration (Anticholenergic, Antihistaminics, etc.).

This study has shown that the frictional force increases with increase in wire dimension. This finding is in concordance with the finding of Tidy, ${ }^{16}$ Sunil Kapila et a ${ }^{15}$ Drescher et al, ${ }^{5}$ Bednar et al, ${ }^{3}$ Adreasen and Quevedo, Janet L Vaughan, David Franco and Frank and Nikolai. ${ }^{3}$ Drescher et al and Frank and Nikolai concluded that frictional resistance between an archwire and bracket was proportional to the occlusogingival wire dimension. In contrast, Baker et $\mathrm{al}^{10}$ suggested that an increase in wire dimension will cause less binding of the wire in the bracket slot and therefore less friction.

This study demonstrated that elastomeric modules used for ligating archwire to bracket produced more frictional resistance than stainless steel ligature wire. This is supported by the finding of Bednar et al, ${ }^{8}$ Frank and Nikolai ${ }^{3}$ and Dickson et al. ${ }^{9}$

The difference in friction between stainless steel ligature wire and elastomeric module indicate differences in the coefficient of friction applicable for these materials sliding in contact with the archwire. ${ }^{16}$

In the recent past, many studies have been conducted by various authors to find the frictional resistance of different archwire to bracket combinations. But none of these authors included Titanium brackets in their studies. In this study, 0.022 " slot Titanium bracket showed more frictional resistance than a 0.022 " slot stainless steel bracket when tested with the same wire specimen. This can be explained on the basis of the coefficient of friction and surface roughness of the two materials. Surface roughness influences friction most directly when dry, unlubricated sliding occurs or when only meager lubrication is present. The effects of roughness depend not only on the degree of surface roughness but also on the geometry of roughness, orientation of roughness features and the relative hardness of the two contacting surfaces. ${ }^{14}$

Since the archwire to bracket play depend on the contact angle between the archwire and the bracket it is imperative on our part to find factors which most influence this. For this study, a formula have been derived to find the contact angle of various archwire to bracket combinations (Fig. 2).

Tidy, ${ }^{16}$ Drescher et al, ${ }^{5}$ Dickson et al ${ }^{4}$ and Baker et a ${ }^{10}$ have suggested that an increased archwire to bracket play results in more friction because of more binding between the archwire and the bracket.

It can be noted from (Table 1) that the contact angle of Mini Uni-Twin bracket (7.6 mm bracket width) with $0.016 \times 0.022^{\prime}$ stainless steel wire is $1.783^{\circ}$. When the bracket width is doubled (Dynalock, Bracket width $3.3 \mathrm{~mm}$ ) the contact angle reduces by $50 \%$ to $0.897^{\circ}$.

Similarly, in both Mini Uni-Twin and Dynalock brackets, when the wire dimension is increased from 0.016 $\times 0.022^{\prime}$ " to $0.017 \times 0.025^{\prime \prime}$ the contact angle decreases from $1.783^{\circ}$ to $0.897^{\circ}$ for Mini Uni-Twin and from $0.865^{\circ}$ to $0.432^{\circ}$ for Dynalock brackets. An increase in wire dimension by 0.001 " reduces the contact angle by $50 \%$. Hence, it can be suggested that wire dimension has got more influence on the contact angle than the bracket width.

Steel SL brackets were consistently reported to show lower friction compared with ceramic and polycarbonate conventional brackets. ${ }^{18-20}$ Clinicians should be cautioned that although in vitro findings are a useful guide to anticipated clinical behavior, the observed clinical performance might be quite different.Loftus. ${ }^{21}$

A novel approach mimicking malocclusions using a three-dimensional setup with nanotechnology transducers appears to have great potential to help us understand the complexity of intra-arch biomechanics and its impact on frictional resistance among other mechanical aspects of orthodontics. $^{22}$

\section{CONCLUSIONS AND CLINICAL SIGNIFICANCES}

Following conclusions were drawn from the study:

1. Narrow brackets generated more friction than wider brackets. Frictional force was inversely proportional to bracket width.

2. Frictional force was directly proportional to wire dimension.

3. Titanium brackets generated more friction than stainless steel brackets. 
4. Archwire and bracket ligated with elastomeric module generated more friction than when ligated with stainless steel ligature wire.

5. Frictional forces in the wet condition were greater than in the dry condition for all archwire to bracket combinations.

The clinical significance of friction is its role in lessening the force actually received by a tooth from an active component such as a spring, loop or elastic. Hence, greater applied force is needed to move a tooth with a bracket archwire combination demonstrating high magnitudes of friction compared with one with a low frictional value.

This has clinical implications in cases demonstrating critical posterior anchorage, such as those requiring reduction of a large overjet. In such malocclusions, one would be wise to use a bracket and archwire combination with a suitable ligation technique that minimizes friction so as to conserve the available anchorage.

A limitation of the study was the difficulty in extrapolating the values for friction determined in vitro to an in vivo situation. This was due to the difficulty of reproducing oral conditions such as muscular and occlusal forces, and tooth movement through bone which may affect the binding of archwire to the bracket.

The study recommends as follows:

1. Use of wide brackets/particularly in cases of major mesiodistal tipping.

2. The use of $0.016 \times 0.022$ " stainless steel wire in $0.018^{\prime \prime}$ I slot as a working arch to provide better spatial root control.

3. The preclusion of brackets with rough surface texture (titanium brackets).

4. Use of stainless steel ligature wire for ligating bracket and archwire to reduce friction.

\section{REFERENCES}

1. Andreasen, Quevedo. Evaluation of friction in $0.022 " \times 0.028$ " standard edgewise bracket in vitro study. J Biomech 1970.

2. Alison Dowing, et al. The effect of artificial saliva on frictional forces between orthodontic brackets and archwire. Br J Orthod 1995;22:41-46.

3. Charles A, Frank, Nikolai. A comparative study of frictional resistances between orthodontic bracket and archwire. Am J Orthod 1980;78:593-609.

4. Dicson JAS, et al. A comparison of the frictional characteristics of five initial alignment wires and stainless steel brackets at three brackets to wire angulations. Am J Orthod 1994;21:15-22.

5. Dieter Drescher, et al. Frictional forces between bracket and archwire. Am J Orthod 1989;96:397-404.

6. Edwards G. The ex vivo effect of ligation technique on static frictional resistance of SS brackets and archwire. BJO 1995;22: 145-53.
7. Garnar L. A comparison of frictional force during simulated canine retraction of a continuous edgewise archwire. Am J Orthod 1986;90:199-203.

8. Bednar J, et al. A comparative study of frictional forces between orthodontic brackets and archwire. Am J Orthod 1991;100: 513-22.

9. Jan GS, et al. Comparative friction of orthodontic wires under dry and wet conditions. Am J Orthod 1986;89:485-91.

10. Baker Kevin L, Lewis G, Nieberg L. Frictional changes in force values caused by saliva substitution. Am J Orthod 1987;91: 31620.

11. Kusy RA, Schaffer DL. Effect of salivary viscosity on frictional coefficient of orthodontic archwire bracket couples. Journal of Materials Science 1995;6:390-95.

12. Kusy RP, Whitley JQ. Comparison of the frictional coefficients for selected archwire-bracket slot combinations in dry and wet state. Angle Orthod 1991;61:223-30.

13. Tselepsis, et al. The dynamic frictional resistance between orthodontic brackets and archwire. Am J Orthod 1994;8: 106-31.

14. Prososki Robert R, Bagby Micheal D. Static frictional force and surface roughness of nickel-titanium archwires. Am J Orthod 1991;100:341-48.

15. Kapila S, Nanda RS. Evaluation of friction between edgewise SS brackets and orthodontic wires of four alloys. Am J Orthod 1990;26:98-117.

16. Tidy DC. Frictional force in fixed appliance. Am J Orthod 1989;96:249-54.

17. Pattern Don H. Frictional resistance of ceramic and brackets. Am J Orthod 1990;98:398-403.

18. Loftus BP, Artun J, Nicholls J, Alonzo TA, Stoner JA. Evalution of friction during sliding tooth movement in various bracketarchwire combinations. Am J Orthod Dentofacial Orthop 1999;116:336-45. Facial Orthop 2005;127:670-75.

19. Shivapuja PK, Berger J. A comparative study of conventional ligation and selfligation bracket systems. Am J Orthod Dentofacial Orthop 1994;106:472-80.

20. Cacciafesta V, Sfondrini MF, Ricciardi A, Scribante A, Klersy C, Auricchio F. Evaluation of friction of stainless steel and esthetic self-ligating brackets in various bracket-archwire combinations. Am J Orthod Dentofacial Orthop 2003;124: 395-402.

21. Esmaili S. Ligation properties of a self-ligating composite bracket: An in vitro study (thesis). Göteborg, Sweden: Göteborg University 2004.

22. Badawi HM, Toogood RW, Carey JP, Heo G, Major PW. Torque expression of self-ligating brackets. Am J Orthod Dentofacial Orthop 2008;133:721-28.

\section{ABOUT THE AUTHORS}

\section{Nadeem Husain \\ (Corresponding Author)}

Reader, Department of Orthodontics, Al-Badar Rural Dental College and Hospital, Gulbarga, Karnataka, India, e-mail: info@dentinova.org

\section{Avinash Kumar}

Assistant Professor, Department of Orthodontics, Al-Badar Rural Dental College and Hospital, Gulbarga, Karnataka, India 